\title{
Microstructural and tribological observations in metallic glass forming alloy layers produced by high-power lasers
}

\author{
D. T. A. Matthews, V. Ocelík \& J. Th. M. De Hosson \\ Department of Applied Physics and Netherlands Institute for Metals \\ Research, University of Groningen, Groningen, The Netherlands
}

\begin{abstract}
Layers of $\mathrm{Cu}$-based metallic glass forming compositions have been produced using high-power lasers. Laser surface remelting and laser cladding techniques provide sufficient cooling rates to form amorphous individual laser tracks and even coatings. The layers have been characterised by SEM, TEM, confocal and optical microscopy which have shown the layers may be fully amorphous, or (nano)crystalline. Hardness testing reveals that high hardness values are attainable for the layers $(>700 \mathrm{HV})$. Shear banding is found to be initiated during indentation testing. The processing of laser remelted layers developed from initial cladding has been analyzed and parameters are outlined which govern layer thickness, track width and ultimately the microstructural appearance of the layers.
\end{abstract}

Keywords: laser cladding, amorphous, hardness, friction.

\section{Introduction}

The formation of surface layers exhibiting differing mechanical properties to their substrate is now a well documented engineering sphere. Advanced coatings are continually being proposed and explored, which also require new processing routes, such as laser cladding, which is still in its relative infancy, particularly with respect to industrial applications on a large scale. Amorphous, amorphous matrix or nanocomposite coatings are one particularly interesting breed of surface modifications since they have been found to exhibit both extreme hardness and toughness [1]. Their application has somewhat been limited to thin, deposited, layers however, which often means that coating adhesion is limited. 
The processing of thicker layers, with direct metallurgical bonding to a substrate has been proposed some time ago [2], with direction being driven towards high cooling rate processes. Laser processing permits very high, local temperatures and subsequent rapid cooling. Significant progress has also been made in the processing of bulk metallic glasses (BMG) in recent times.

Examples for attractive Glass Forming Alloys (GFA) include the Cu-Ti-Zr-Ni system and some of its derivatives $[3,4]$. Their application as possible surface layers has been investigated by several research groups and not least by the authors, who show that direct laser remelting of a BMG layer may lead to fully amorphous layers, which exhibit outstanding tribological properties $[5,6]$. The goal of dual deposition and attainment of amorphous layers has proved somewhat more difficult however, and the reasons for that, progress and properties attainable in layers clad on Ti-(alloy) substrates are outlined in this article.

\section{Experimental procedure}

Spark-erosion cut and de-greased Ti-alloy $(10 \mathrm{~cm} \times 10 \mathrm{~cm})$ have been selected for the application of Ti-containing metallic glass forming alloys. Since, during laser treatments, some of the applied energy may be reflected away from the target, the substrate surface is fine sand blasted to reduce the reflectivity, ergo improving the efficiency of the laser processing. The laser cladding and remelting processes were conducted over a range of processing parameters which will be specified as appropriate with a $2 \mathrm{~kW}$ Rofin-Sinar Nd-YAG laser. For all samples deposited on the Ti-alloy, the carrying (delivered at $31 / \mathrm{min}$ ) and shielding gas (101/min) was argon. The composition of the single track layer was varied by manipulating the feeding rates of a twin hopper powder feeder for a $\mathrm{Zr}$ $\mathrm{Ni}$ mix and pure $\mathrm{Cu}$. The powders were purchased commercially and all were at least $99.99 \%$ pure. The laser remelted layers were again fed from a twin hopper, with parameters varied to optimise the required composition of BMG production. All resultant fabrications are investigated by optical microscopy, secondary electron microscopy with energy dispersive spectroscopy (SEM with EDS) (Philips XL-30 (The Netherlands)), (high resolution) transmission electron microscopy ((HR)TEM) (FEG Jeol 2010 (Japan)) with in-situ heating and EELS capability. Hardness and scratch test examinations are conducted on a CSM Revetester (Switzerland), using a Standard Vickers geometry indenter for hardness measurements and a $200 \mu \mathrm{m}$ radius Rockwell C diamond stylus as the scratch counterface. The indenter load was 2 or $4 \mathrm{~N}$ for the Ti-containing coatings. Confocal microscopy ( $\mu$ Surf Nanofocus Messtechnik) was also used to characterise the scratch geometries.

\section{Results and discussions}

The laser cladding technique is well documented and a broader overview, including a schematic overview can be found elsewhere [7]. Various parameters may be manipulated to vary the coating properties. The first stage is the 
deposition of the layers. In the first instance of this investigation, many layers were deposited at different parameters to gain an understanding of the standard laser cladding technique, and in the second stage a single track is deposited at a relatively slow scanning speed $(500 \mathrm{~mm} / \mathrm{min})$ to achieve good metallurgical bonding at the coating/substrate interface. The layer may then be remelted at a rate required to develop amorphous layers - previous investigations have shown that $8 \mathrm{~mm} / \mathrm{min}$ scan speed and $+6 \mathrm{~mm}$ defocus is sufficient to process fully amorphous layers $300 \mu \mathrm{m}$ deep in $\mathrm{Cu}_{47} \mathrm{Ti}_{33} \mathrm{Zr}_{11} \mathrm{Ni}_{6} \mathrm{Sn}_{2} \mathrm{Si}_{1}$ BMG alloy [6]. The coatings deposited in the investigation have been achieved in relation to several Ti-containing metallic glass forming alloys.

\subsection{Ti-containing layers}

A summary of the track dimensions attainable with varying parameters for the $\mathrm{Cu}-\mathrm{Ti}-\mathrm{Zr}-\mathrm{Ni}$ alloy are shown in Table 1. The hardness profiles for these alloys are shown in Figure $1 \mathrm{a}$ and $\mathrm{b}$ for changes in scanning speed and powder feed rate. The laser power was kept at $1200 \mathrm{~W}$ for all examples. Other constants were Ar shielding/carrying gas - this was maintained at 15 and $11 / \mathrm{min}$ respectively; beam defocus $(+8 \mathrm{~mm})$ and nozzle angle $\left(58^{\circ}\right)$ and the nozzle was positioned so that the powder was fed "in front" of the laser beam by a displacement of 0.5 $\mathrm{mm}$. The entire Ti proportion in the clad layer was developed through dilution from the substrate. As seen in Table 1, the dilution was around 55-68\%. This means that the composition may easily be altered by simple manipulation of the cladding parameters. It is evident from this table that a change in scanning speed has more effective on the track dimensions than a change in powder feeding rate.

Table 1: Table revealing the effect of Cladding Parameters on Track Width, depth and dilution for $\mathrm{Cu}-\mathrm{Ti}-\mathrm{Zr}-\mathrm{Ni} \mathrm{BMG}$ alloys.

\begin{tabular}{cccccc}
\hline $\begin{array}{c}\text { Sample } \\
\text { ID }\end{array}$ & $\begin{array}{c}\text { Scanning } \\
\text { Speed } \\
\mathbf{m m} / \mathbf{m i n}\end{array}$ & $\begin{array}{c}\text { Total Powder } \\
\text { Feeding Rate } \\
\mathbf{g} / \mathbf{m i n}\end{array}$ & $\begin{array}{c}\text { Track } \\
\text { Width } \\
\mathbf{m m}\end{array}$ & $\begin{array}{c}\text { Track } \\
\text { Depth } \\
\boldsymbol{\mu m}\end{array}$ & $\begin{array}{c}\text { Dilution } \\
\mathbf{\%}\end{array}$ \\
\hline A & 1000 & 34.5 & 2.85 & 855 & 62 \\
B & 1500 & 34.5 & 2.2 & 650 & 60.7 \\
C & 2000 & 34.5 & 1.92 & 630 & 55.6 \\
D & 2500 & 34.5 & 1.73 & 515 & 58.3 \\
E & 3000 & 34.5 & 1.6 & 440 & 68.2 \\
F & 1500 & 23 & 2.1 & 635 & 63 \\
G & 1500 & 27.6 & 2.2 & 700 & 57.1 \\
H & 1500 & 31.9 & 2.2 & 680 & 62.5 \\
I & 1500 & 36.3 & 2.44 & 735 & 54.4 \\
\hline
\end{tabular}


The hardness profiles for several of the layers are shown in Figure 1 ((a) and (b)). For the layers produced at varying scan speed, the thickness was too large and hence the layers contained high internal stresses which were released as cracks. Therefore, Figure 1a only reveals results for 2 scanning speeds, 2500 $\mathrm{mm} / \mathrm{min}$ and $3000 \mathrm{~mm} / \mathrm{min}$, which were significantly fast to enable well bound, crack free clad layers. The results show that the hardness is high (700-800 HV0.4), and that, interestingly, the highest hardness is at some depth below the surface in both cases. This is due to compressive (or less tensile) stresses forming in the base of the clad, and is advantageous in terms of creating a functional gradient in the layer. Given that hardness, $\mathrm{HV}$ is related to yield stress, $\sigma_{\mathrm{y}}$, such that $\mathrm{HV} \sim 3 \sigma_{\mathrm{y}}$ the increase of around $100 \mathrm{HV}(1000 \mathrm{MPa})$ equates to a difference in internal stresses of around $300 \mathrm{MPa}$, which is an acceptable value for laser clad layers [8]. The discrepancies between the depth noted in Table 1 and the hardness profile 'depth' arises due to the fact that not all profiles were able to be taken through the track centre, since the values are an average of several profiles. Rogue values were removed from the results. The marked increase in dilution at fast (2.5 and $3 \mathrm{~m} / \mathrm{min}$ scan speed) may also play a role in the better bonding through the layer. The reason for the increased dilution is expected to be a result of the non-equilibrium conditions associated with laser cladding. The total track depth is seen to reduce in accord with the increased scan speed; however the increase in scan speed does not affect the effect of powder feeding rate and laser penetration in the same ways. The inflexion in the dilution values shows this clearly. The beam energy does not penetrate deeper into the substrate, but since the powder feeding rate is constant, the powder amount per unit length is lower. Thus whilst the total clad depth is reduced, the percentage of the clad which comes from the substrate increases. If the beam power (energy density) is kept constant, and the powder feeding rate changed, the effect is not so marked. This is seen clearly in the hardness results which will now be discussed.

No porosity was seen in the layers and the highest hardness, in all cases, was never found at the surface but instead at some depth below the surface. In the case of the change in scan speed, the slightly slower processed alloy actually provides (marginally) the higher hardness. This is a little surprising, but can be explained by the increased dilution at $3 \mathrm{~m} / \mathrm{min}$ scan speed compared to the dilution at $2.5 \mathrm{~m} / \mathrm{min}$, which is described earlier.

If the hardness profile in Figure $1 \mathrm{~b}$ is viewed, it is seen that the layer depth is not significantly altered by changes in powder feeding rate. The most "stable" deposition appears to result from the layer deposited with a total of $27.6 \mathrm{~g} / \mathrm{min}$ [Sample G, Table 1] since the hardness is most constant across the full coating depth. The most unstable layer is that with the highest feeding rate - Sample I, Table $1-38.3 \mathrm{~g} / \mathrm{min}$. This indicates that for this particular system at the prescribed processing parameters, a feeding rate of $23-28 \mathrm{~g} / \mathrm{min}$ generates the best clad layers.

It is interesting to view the indents since no indents caused cracking. Some indents however, did exhibit apparent shear banding - an example of this is shown in Figure 2 (a), an indent taken from a $\mathrm{Cu}-\mathrm{Ti}-\mathrm{Zr}-\mathrm{Ni}$ layer clad at 2000 
$\mathrm{mm} / \mathrm{min}$ [Sample C, Table 1] which was poorly bonded overall and significant clad-cracking was observed, however the hardness (where measurable) of such a clad was almost 1000 HV0.2, and the 4-side shear banding in Figure 2(a) provides a very strong indication that partially amorphous layers are attainable by single pass laser cladding. An indent from a $2500 \mathrm{~mm} / \mathrm{min}$ scan speed layer [Sample D, Table 1] is shown in Figure 2(b), showing the shear band phenomenon in more detail. At lower cladding speeds evidence of shear banding is again apparent, however if the scan speed and powder feeding rate is reduced (for example $1500 \mathrm{~mm} / \mathrm{min}$ [Sample F, Table 1] Figure 2(c)), the cooling rate is not so fast and the microstructure is seen to be a fine matrix, containing Ti-rich dendrites and no cracking or shear banding is formed.
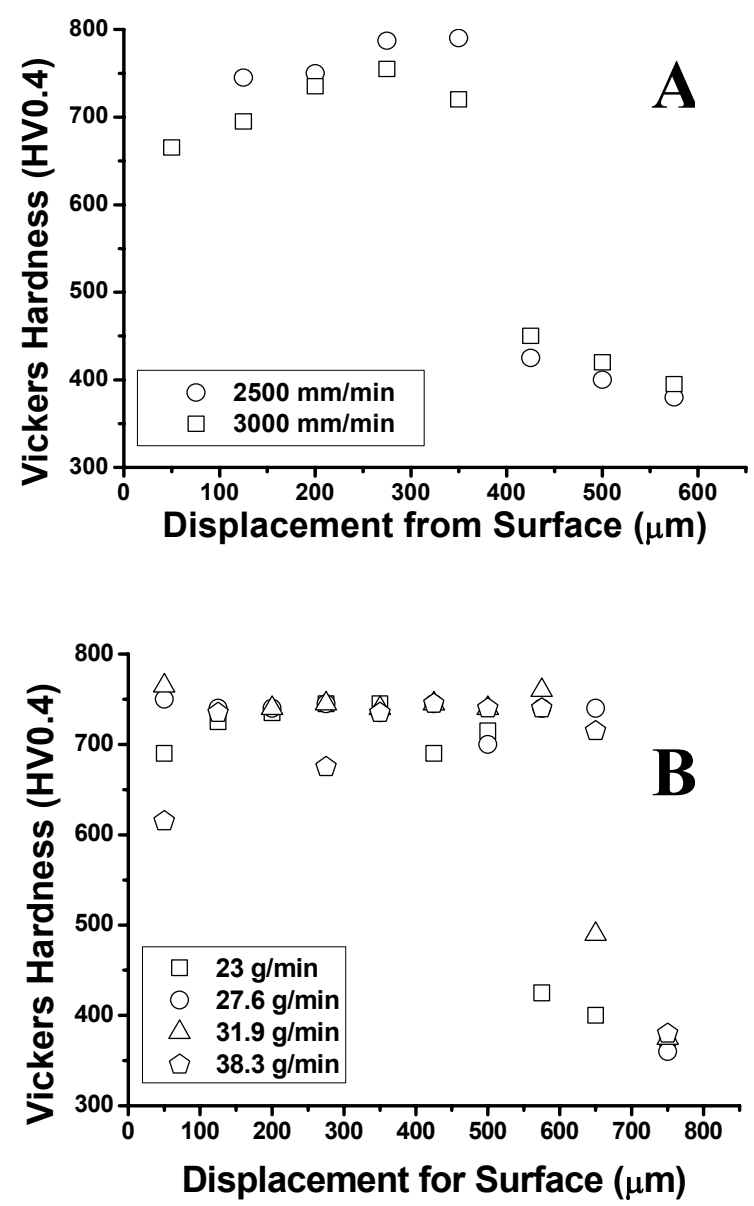

Figure 1: (a) Hardness profiles for laser clad layers produced at 2.5 and 3 $\mathrm{m} / \mathrm{min}$ scan speed and constant powder feeding rate [Samples D and E, Table 1] and (b) for constant scan speed, but changing powder feeding rates [samples F-I, Table 1]. 


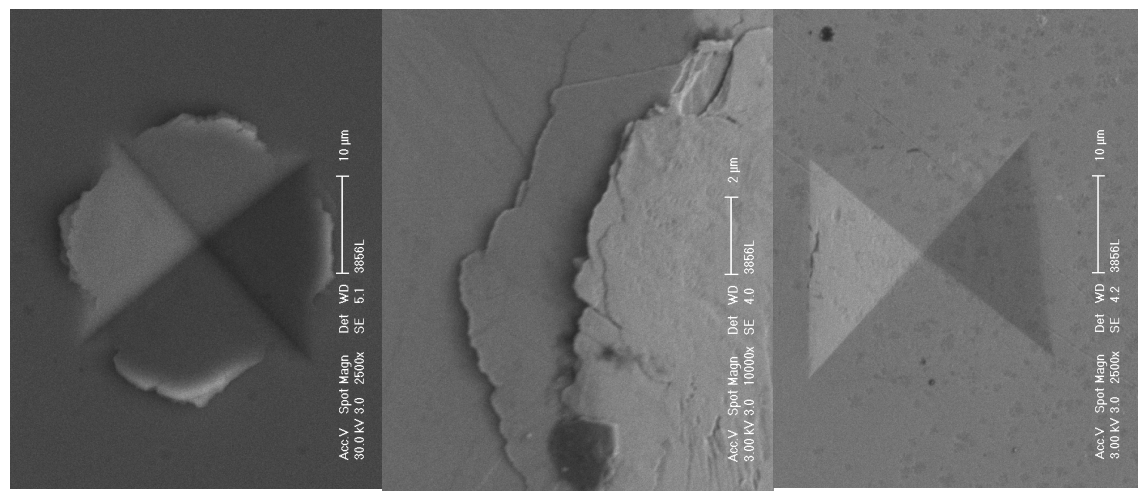

Figure 2: $\quad \mathrm{SEM}$ micrographs for $\mathrm{Cu}-\mathrm{Ti}-\mathrm{Ni}-\mathrm{Zr}$ laser clad layers having undergone microhardness investigations (a) an indent in Sample D, Table 1 laser clad layer exhibiting 4-side shear banding (b) higher magnification image of the shear band development in sample E, Table 1 and (c) Sample F, Table 1 showing a fine eutectic matrix reinforced with Ti-dendrites which exhibits no peripheral deformation.

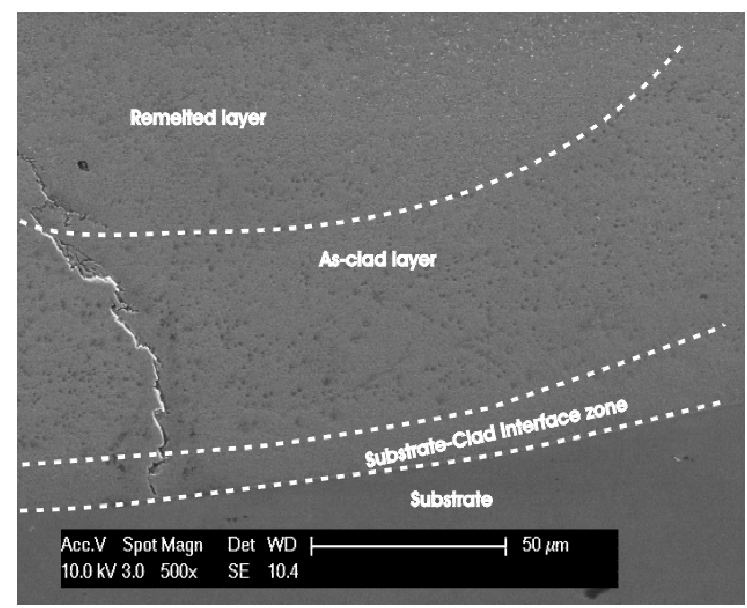

Figure 3: $\quad$ SEM micrograph revealing the zones of a clad and remelted GFA layer on a Ti-alloy substrate.

This relatively slow development of a well-bound layer is highly encouraging and in the instance of a clad and remelted layer (Figure 3), the composition $\mathrm{Cu}_{47} \mathrm{Ti}_{33} \mathrm{Zr}_{11} \mathrm{Ni}_{6} \mathrm{Sn}_{2} \mathrm{Si}_{1}$ was chosen for investigation. The layer forms featureless regions, indicating that rapid cooling is achieved; the cooling rate is too low and therefore prevents a fully amorphous layer forming at the prescribed treatment conditions. The flipside of this is that a thicker layer may be attained, and the mechanical properties between the layer and the substrate are more evenly 
graded. Upon remelting, however, the faster cooling also leads to higher stresses being developed within the layer, and these are often released by cracking, which may propagate to the as-clad region (Figure 3 ). The atomic \% composition was confirmed at the track centre to be that of $\mathrm{Cu}_{47} \mathrm{Ti}_{33} \mathrm{Zr}_{11} \mathrm{Ni}_{6} \mathrm{Sn}_{2} \mathrm{Si}_{1}$, in accordance with that desired/expected.

The hardness of the as-clad region was found to be slightly lower (670-700 HV0.2) than the remelted area (850-890 HV0.2), as expected (Figure 4(a)). This is due to the enhanced cooling afforded by the rapid scan speed and subsequent refinement of the microstructure. It is also interesting to note, in terms of functionally grading, not only a coating, but also the coating-substrate system, that the hardness of titanium substrate was significantly increased after treatment to a depth of over 200 microns beyond the clad layer. The hardness in this area was 425 Vickers, whilst the hardness of the substrate $1 \mathrm{~mm}$ away from the clad layer was only 300 Vickers.
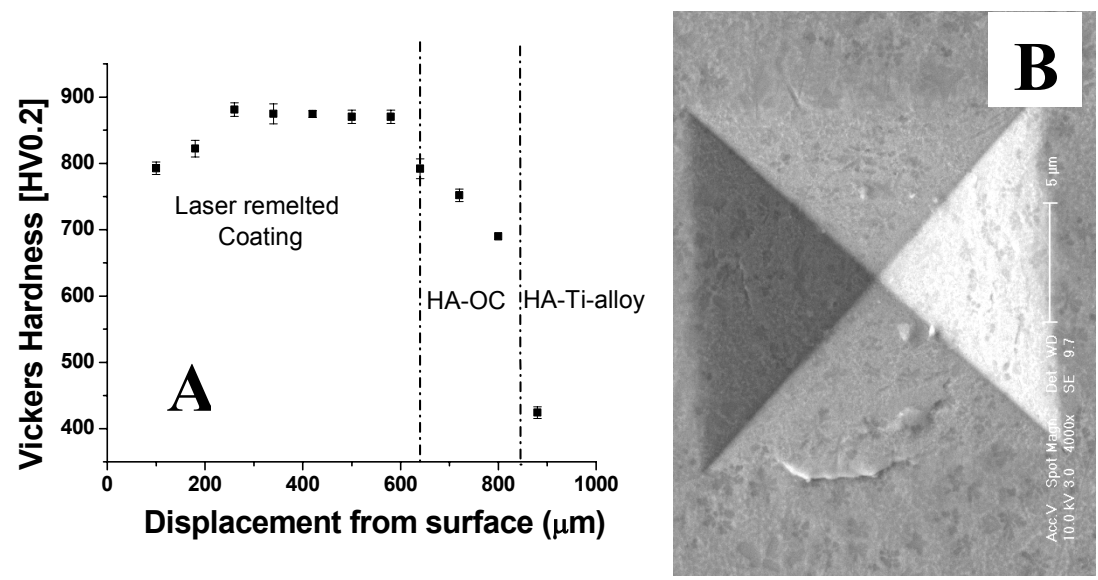

Figure 4: (a) Hardness profile of a laser clad and remelted layer of $\mathrm{Cu}_{47} \mathrm{Ti}_{33} \mathrm{Zr}_{11} \mathrm{Ni}_{6} \mathrm{Sn}_{2} \mathrm{Si}_{1}$ composition and (b) SEM micrograph of a Vickers indent from the centre of that layer revealing shear banding.

The increased 'remelt depth' and heat effects on the titanium substrate are a direct consequence of the low thermal conductivity of titanium. Again, the indentation method appears to induce shear band formation (Figure 4(b)), which indicates that the layer may have amorphous constituent regions. Together with the desired composition achieved, this is very promising, since this procedure involves the deposition of a 5 element powder mix.

TEM observations from the remelted area (an example is shown in Figure 5) show that some areas are amorphous in nature, which may explain the observation in Figure 4(b) that hardness testing induced shear band development in the matrix of the clad layer. There is, however, a greater proportion of crystalline content, with the crystals being for the order of $5 \mathrm{~nm}$ up to 2 microns. 


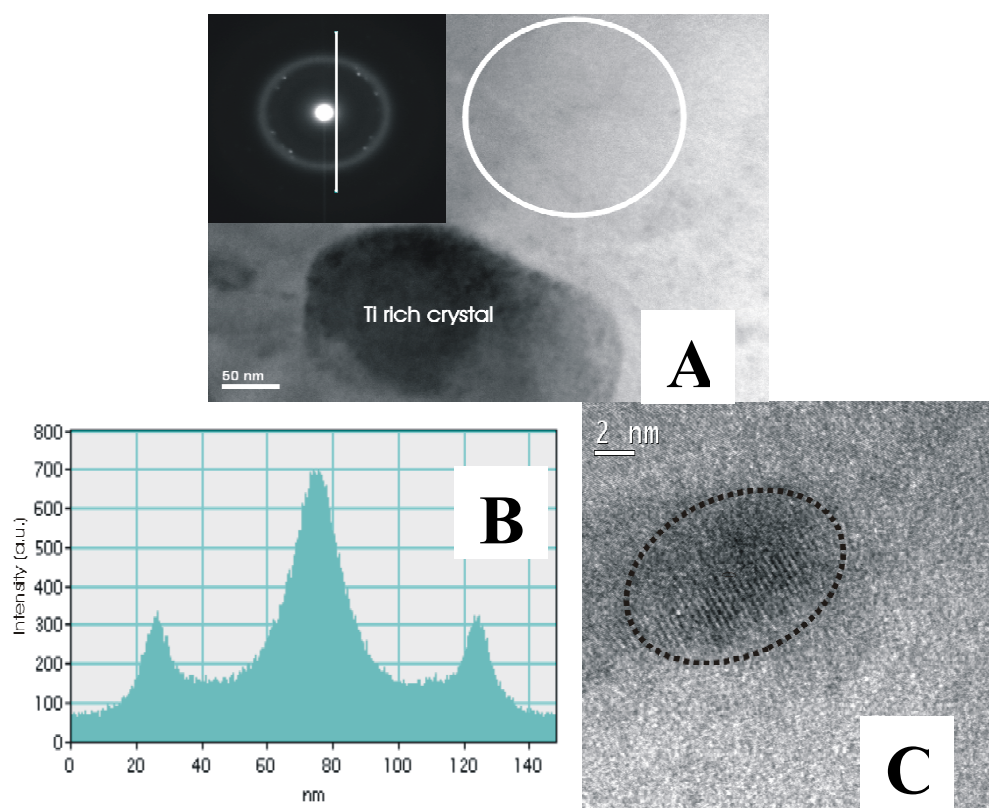

Figure 5: TEM observation revealing an amorphous matrix (see diffraction insert proved by the line scan in (b)) surrounding a Ti-rich crystal around $250 \mathrm{~nm}$ in size and (c) High resolution TEM micrograph revealing a $5 \mathrm{~nm}$ size Ti-rich crystal surrounded by an amorphous matrix.

\subsection{Scratch observations and friction coefficient}

For these $\mathrm{Cu}_{47} \mathrm{Ti}_{33} \mathrm{Zr}_{11} \mathrm{Ni}_{6} \mathrm{Sn}_{2} \mathrm{Si}_{1}$ laser remelted layers, the hardness of the layers is promising in terms of mechanical performance. Scratch testing allows information to be gained as regards tribological performance and even hardness characteristics. One parameter attained from scratch testing is the friction coefficient. Single pass friction is very low for the $\mathrm{Cu}$-based layer, (0.032) and repeated scratch testing actually leads to an even lower friction coefficient. This is shown in Figure 6 and signifies that whilst extreme hardness promotes beneficial properties, it can be more advantageous to temper that with a fine microstructure that more readily accepts deformation and provides a ductile counterface as opposed to a brittle one. The dimensions of these tracks are, for 1 pass, depth $=1.3 \mu \mathrm{m}$, width $=71.16 \mu \mathrm{m}$ and for 50 passes depth $=2.1 \mu \mathrm{m}$ and width $=80.93 \mu \mathrm{m}$ (including edge pile-up).

\section{Summary and conclusions}

Properties such as low friction, good wear resistance, high hardness and thermal stability up to $350^{\circ} \mathrm{C}$ of metallic glasses and layers thereof have been found to be 
highly attractive. A high-power laser has been proven to be a tool capable of producing such layers. Actual laser cladding, and subsequent remelting of metallic glass compositions have been attempted and proven to be achievable and successful. Laser clad layers have been produced using premixed powders of compositions which are know to promote metallic glass (amorphous structure) formation. Surface coatings of metallic glass forming compositions have been administered to Ti with degrees of success.

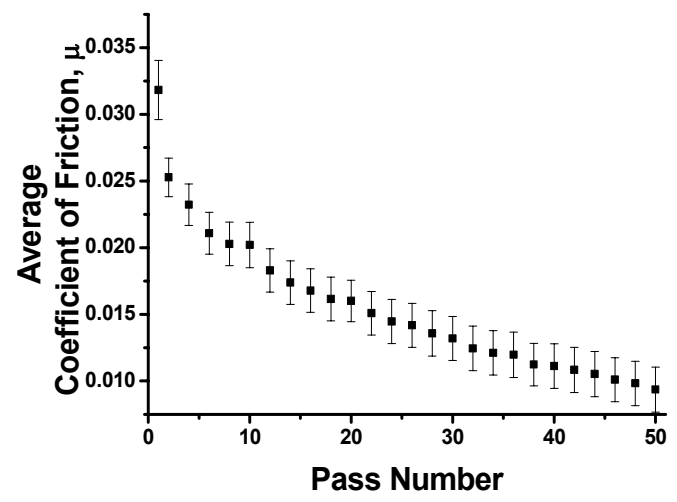

Figure 6: Graph showing the average friction coefficient vs. pass number for a $\mathrm{Cu}_{47} \mathrm{Ti}_{33} \mathrm{Zr}_{11} \mathrm{Ni}_{6} \mathrm{Sn}_{2} \mathrm{Si}_{1}$ laser clad and remelted layer.

Firstly, the surface layers produced on both substrates exhibit excellent substrate-coating metallurgical bonding. The hardness of all $\mathrm{Cu}$-based coatings has been found to be over 700 HV0.4. The indentation experiments exhibit shear band formation in some of the rapidly processed layers. The friction coefficient of all layers was seen to be super-low and after service the friction was seen to reduce to an even lower value of $0.00936 \pm 0.00168$ for the $\mathrm{Cu}$-based remelted coatings.

\section{References}

[1] Y.T. Pei, D. Galvan and J. Th. M. De Hosson, Nanostructure and Properties of TiC/a-C:H composite coatings, Acta Materialia, 53, pp. 4505-4521 (2005)

[2] F. Aubert, R. Colaco, R. Villar and H. Sirkin, Production of glassy metallic layers by laser surface treatment, Scripta Materialia 48, pp. 281$286(2003)$

[3] X.H. Lin and W.L. Johnson, Formation of Ti-Zr-Cu-Ni bulk metallic glasses, Journal of Applied Physics 48 (11), pp. 6514-6519 (1995)

[4] E.S. Park, H.K. Lim, W.T. Kim and D. H. Kim, The effect of Sn addition on the glass-forming ability of $\mathrm{Cu}-\mathrm{Ti}-\mathrm{Zr}-\mathrm{Ni}$-Si metallic glass alloys, Journal of non-crystalline solids 298, pp. 15-22, 2002 
[5] D.T.A. Matthews, V. Ocelík and J. Th. M. de Hosson, Scratch Test Induced Shear Banding in High Power Laser Remelted Metallic Glass Layers, Journal of Materials Research (February 2007), in press

[6] D.T.A. Matthews, V. Ocelík, and J. Th. M. de Hosson, Metallic glass layers produced by high power lasers, Bulk Metallic Glasses, TMS 2006, pp. 99-108 ISBN 978-0-87339-612-7

[7] W.M. Steen, Laser Surface Treatment An Overview, Laser Processing: Surface Treatment and Film Deposition, (eds. J. Mazumder, O. Conde, R. Villar and W. Steen), NATO ASI Series (1996)

[8] U. Oliveira, V. Ocelik, J. Th. M. De Hosson, Residual stress analysis in Co-based laser clad layers by laboratory X-rays and synchrotron diffraction techniques, Surface and Coatings Technology, 201, pp. 533$542(2006)$ 